\title{
Situação sorológica e vacinal para Hepatite B em puérperas de uma maternidade pública
}

\author{
Hepatitis B serologic and vaccination status in postpartum women at a public maternity hospital \\ La situación serológica y vacunal contra la Hepatitis B en mujeres durante el posparto en una \\ maternidad pública
}

\author{
Verbênia Cipriano Feitosa ${ }^{I}$; Telma Maria Evangelista de Araújo ${ }^{I I}$; Inez Sampaio Nery ${ }^{I I I}$; Silvana Santiago da Rocha ${ }^{I V}$
}

\begin{abstract}
RESUMO: A Hepatite B é uma infecção viral que se destaca pela alta morbimortalidade, cronicidade, cirrose e carcinoma hepatocelular. Esta pesquisa objetivou avaliar a situação sorológica e vacinal para Hepatite B em puérperas internadas em uma maternidade pública de Teresina. Trata-se de um estudo transversal, realizado por meio de entrevistas com 377 puérperas, entre janeiro a fevereiro de 2011. A baixa cobertura vacinal caracterizou-se pelas oportunidades perdidas de vacinação, pois $77,5 \%$ delas não receberam nenhuma dose da vacina, embora a maioria tenha realizado o pré-natal. Apenas 41,9\% realizaram sorologia. Em relação às informações sobre a vacina, observa-se que 77,3\% das puérperas foram informadas sobre as vacinas que deveriam receber durante o pré-natal. Dentre as fontes informantes, o enfermeiro foi o mais citado, com 55\%, reforçando o seu papel de destaque como um educador em saúde na atenção pré-natal. Evidenciou-se a ocorrência de baixas coberturas sorológica e vacinal, denunciando a ineficiência do acompanhamento pré-natal.

Palavra-Chave: Cobertura vacinal; sorologia; hepatite B; puerpério.
\end{abstract}

ABSTRACT: Hepatitis B is a viral infection notable for high rates of morbidity, chronicity, cirrhosis and hepatocellular carcinoma (HCC). This transversal study to evaluate serologic and Hepatitis B vaccination status in women admitted to a public maternity hospital in Teresina was conducted in January and February, 2011, through interviews of a sample of 377 postpartum women. Poor vaccine coverage was characterized by missed opportunities for immunization: $77.5 \%$ of the sample received no dose of the vaccine, even though most had received antenatal care. Hepatitis serology testing had been performed on only $41.9 \%$. However, $77.1 \%$ were informed of what vaccines they should receive during the antenatal period. Nurses were the information source most mentioned (by 55\%), underlining their key role as health educators in antenatal care. The study found low vaccine and serological coverage, evidencing the inefficiency of antenatal monitoring.

Keywords: Immunization coverage; serology, hepatitis B; puerperium.

RESUMEN: La Hepatitis B es una infección viral que se caracteriza por la alta morbimortalidad, cronicidad, cirrosis y carcinoma hepatocelular. Esta investigación tuvo como objetivo evaluar la situación serológica y vacunal contra la Hepatitis B en mujeres en el periodo de posparto internadas en una maternidad pública de Teresina. Se trata de un estudio transversal, realizado a través de entrevistas junto a 377 mujeres en el posparto, entre enero y febrero de 2011. La baja cobertura vacunal se ha caracterizado por las oportunidades perdidas de vacunación, ya que el 77,5\% no recibió ninguna dosis de vacuna, aunque la mayoría haya realizado el prenatal. Sólo el 41,9\% realizó serología. En cuanto a las informaciones acerca de la vacuna, se observa que el 77,1 \% de las mujeres en posparto fue informado acerca de las vacunas que se deben tomar en el período prenatal. Entre las fuentes informantes, el enfermero fue el que más se ha mencionado, en 55\%, lo que refuerza su papel de destaque como un educador de salud en la atención prenatal. Reveló la existencia de bajas coberturas serológicas y vacunal, denunciando la ineficiencia de la atención prenatal. Palabras Clave: Cobertura vacunal; serología; hepatitis B; posparto.

\section{INTRODUÇÃO}

A Hepatite B é uma doença infecciosa de origem viral, considerada na atualidade um importante problema de saúde pública no Brasil e no mundo. Muitas vezes, os portadores do vírus da Hepatite B (VHB) nem sabem que possuem esta condição, o que tem contribuído para o aumento significativo da ocorrência de transmissões verticais, pois nem sempre são adotadas medidas corretas com o recém-nascido (RN) no momento do parto.

O desenvolvimento da vacina contra Hepatite B foi uma das maiores conquistas científicas das últimas três décadas. Entretanto, a morbimortalidade ainda persiste, destacando-se como uma das principais causas de doenças hepáticas, associada, em sua forma crônica,

IMestre em Enfermagem, Universidade Federal do Piauí. Teresina, Piauí, Brasil. E-mail: verbeniafeitosa@gmail.com.

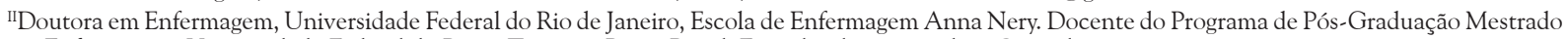
em Enfermagem, Universidade Federal do Piauí. Teresina, Piauí, Brasil. E-mail: telmaevangelista@gmail.com.

IIIDoutora em Enfermagem, Universidade Federal do Rio de Janeiro, Escola de Enfermagem Anna Nery. Docente do Programa de Pós-Graduação Mestrado em Enfermagem, Universidade Federal do Piauí. Teresina, Piauí, Brasil. E-mail: ineznery.ufpi@gmail.com.

${ }^{\mathrm{IV}}$ Doutora em Enfermagem, Universidade Federal do Rio de Janeiro, Escola de Enfermagem Anna Nery. Docente do Programa de Pós-Graduação Mestrado em Enfermagem, Universidade Federal do Piauí. Teresina, Piauí, Brasil. E-mail: silvanasantiago27@gmail.com. 
com cirrose e carcinoma hepatocelular (CHC). Além disso, o número de indivíduos infectados pelo VHB é cerca de 10 vezes maior do que aqueles com Vírus da Imunodeficiência Humana (HIV) ${ }^{1}$.

A Organização Mundial de Saúde (OMS) estima que mais de 350 milhões de indivíduos estejam infectados no mundo e 200.000 casos novos são detectados por ano nos Estados Unidos. Destes, apenas 33 a 50\% são sintomáticos. Cerca de 5\% ou 12,5 milhões de pessoas foram infectadas e $10 \%$ destas apresentaram infecção crônica ${ }^{2}$.

No Brasil, a situação também é preocupante. Segundo o Ministério da Saúde (MS), a estimativa é de que $15 \%$ da população já foi exposta ao VHB e 1\% sofra de Hepatite B crônica. Estudo realizado antes da política de vacinação contra a hepatite $B$ apontava três padrões de distribuição deste vírus no Brasil: alta endemicidade na Região Amazônica, parte do Espírito Santo e Oeste de Santa Catarina; endemicidade intermediária, nas Regiões Nordeste, Centro-Oeste e Sudeste e baixa endemicidade, na Região Sul do país. Entretanto, após a introdução da vacina, esse padrão vem se modificando em todas as regiões do país. Portanto, a Região Nordeste, atualmente, foi considerada em situação de baixa endemicidade ${ }^{3}$.

A baixa endemicidade no Nordeste, sobretudo no Piauí, pode estar relacionada ao reduzido número de notificações, o que compromete um diagnóstico real da situação da Hepatite B nessa região. No Piauí, em 2004, foram confirmados 777 casos de hepatites virais, sendo o sétimo estado da Região Nordeste em números de casos. Desse total, a etiologia estava indefinida em 25\% deles, demonstrando que a vigilância e o diagnóstico necessitavam ser incrementados. Nesse mesmo ano, as taxas de mortalidade por Hepatites B e C no Piauí foram menores do que a média regional e nacional. Em 2008, foram registrados, no Sistema de Informação de Agravos de Notificação (SINAN) do Piauí, 792 casos de hepatites virais e, em 2009, houve uma redução do número de notificações para 335 e entre os casos confirmados, 102 foram positivos para Hepatite $\mathrm{B}^{4}$. Contudo, estudo realizado no período de 2007 a 2010 verificou que o Piauí apresentou 746 casos de Hepatite $\mathrm{B}$ aguda confirmada laboratorialmente $\mathrm{e}^{5}$ Os autores da referida pesquisa questionam as informações contidas no SINAN do Estado do Piauí, em relação à Hepatite B.

Diante das estatísticas, verifica-se a importância da adoção de estratégias para a prevenção e controle da disseminação do VHB. Uma delas diz respeito ao início precoce da assistência pré-natal, momento no qual a sorologia deve ser realizada. E, frente à detecção da infecção, as medidas terapêuticas deverão ser instituídas, assim como a profilaxia em relação à transmissão da infecção. Na gestante, uma medida preventiva é a solicitação do teste sorológico para Hepatite $B$ no primeiro trimestre e na $32^{\mathrm{a}}$ semana de gestação e vacinação contra Hepatite $\mathrm{B}$ em gestantes em qualquer época da gravide $z^{6,7}$.
A vacinação deve ser uma prática incorporada no cotidiano das unidades de saúde, devendo, portanto, deixar de ser exclusiva de serviços de atenção primária, passando a incorporar outros tipos de serviço, como, por exemplo, as maternidades, para que não se perca nenhuma oportunidade de vacinação. Para que a Hepatite B se mantenha sob controle, é necessária uma cobertura vacinal mínima de 95\% ${ }^{4,8}$.

Segundo dados da Coordenação Estadual de Imunização do Piauí, a cobertura vacinal de Hepatite B acumulada no período de 1994 a setembro de 2011 em crianças com até 1 ano de vida foi de 95,8\%; na faixa etária de 5 a 10 anos alcançou 104,5\%; nas demais faixas etárias não atingiu o mínimo recomendado pelo Programa Nacional de Imunização (PNI), sendo 78,3\% para 11 a 14 anos, 44,5\% de 15 a 19 anos e apenas 30,3\% para a faixa etária de 20 a 24 anos $^{9}$. A baixa cobertura vacinal da Hepatite B em jovens, entre estes, mulheres em plena idade reprodutiva, configura uma situação preocupante na prevenção da infecção nesta fase da vida. Frente ao exposto, este estudo objetivou avaliar a situação sorológica e vacinal para Hepatite $B$ em puérperas atendidas em uma maternidade pública de Teresina.

\section{REVISÃo DE LITERATURA}

A Hepatite B continua, nos dias atuais, sendo uma das principais causas de doença hepática no mundo. Calcula-se que em torno de um milhão de pessoas morrem por complicações da doença hepática a cada ano. A Hepatite B crônica tem se revelado uma doença complexa, de difícil manejo, em função de peculiaridades na relação vírus-hospedeiro, surgimento de mutantes, heterogeneidade viral e diversidade das formas clínicas ${ }^{10}$.

No Brasil, a vacina contra Hepatite B foi introduzida em 1998, quando o PNI recomendou a vacinação universal das crianças no primeiro ano de vida, a partir do nascimento. Em 2001, a faixa etária foi ampliada até 19 anos de idade. Posteriormente, em 2009, foi estendida a todo o território nacional para grupos considerados mais vulneráveis, como gestantes, trabalhadores de saúde, bombeiros, policiais militares e civis, entre outros. No ano de 2011, foi ampliada para a faixa etária de 24 anos; em 2012, estendeu-se até os 29 anos $^{11}$. Em 2013, tem-se nova ampliação, dos 30 aos 49 anos $^{12}$.

Atualmente, o PNI disponibiliza a vacina contra Hepatite $\mathrm{B}$ para todas as salas de vacinação do país. $\mathrm{O}$ esquema de vacinação para crianças é composto por quatro doses, sendo a $1^{\mathrm{a}}$ (monovalente) administrada ao nascimento, a $2^{\text {a }}$ (pentavalente) aos dois meses, a $3^{\mathrm{a}}$ aos quatro e a $4^{\mathrm{a}}$ aos seis meses ${ }^{13}$. Cada dose é de 0,5 $\mathrm{ml}$ em menores de 20 anos e de $1 \mathrm{ml}$ em maiores de 20 anos, por via intramuscular, não devendo ser feita na região glútea em função da maior quantidade de tecido adiposo no local, tendo indicação o músculo vasto lateral da coxa em crianças e o músculo deltóide em adultos. Não há contraindicação específica ${ }^{11}$. 
Observa-se que, no Brasil, o acesso à vacina e ampliação da sua oferta abrangeu uma grande parcela da população. Todavia, faz-se necessário a conscientização tanto da comunidade como dos profissionais de que a eliminação da transmissão do VHB só será possível se realmente estas medidas forem colocadas na prática cotidiana dos serviços de saúde e se a população, principal beneficiada, fizer valer os seus direitos à saúde, cumprindo o seu papel de cidadã.

\section{Metodologia}

Trata-se de um estudo epidemiológico, transversal e documental, mediante a avaliação dos registros do cartão de pré-natal, considerando as variáveis referentes às doses de vacina da Hepatite B. A população do estudo foi composta por puérperas, internadas em uma maternidade pública de Teresina, utilizando-se amostragem aleatória, com base na média mensal de partos $(n=950)$ e um erro tolerável de 4\% (n=377). Adotou-se como critério de exclusão estar sem condição clínica de responder às questões de interesse do estudo. Apenas três foram excluídas, redundando em 374. A coleta de dados ocorreu no período de janeiro a fevereiro de 2011, por meio de entrevistas e avaliação do cartão de pré-natal de cada puérpera. $\mathrm{O}$ instrumento foi um formulário contendo as seguintes variáveis: idade gestacional na primeira consulta, acompanhamento pré-natal, local do pré-natal, número de doses recebidas da vacina Hepatite $\mathrm{B}$, realização do teste sorológico para Hepatite B, informações das puérperas sobre vacinas e a fonte informante.

Os dados foram digitados com a utilização do software Statistical Package for the Social Science (SPSS). Para buscar a associação da sorologia e vacinação para Hepatite B com os aspectos sociodemográficos e perinatais das puérperas, foi utilizado o teste de quiquadrado com o respectivo valor de p e Odds Ratio.

Às puérperas foi oferecido o Termo de Consentimento Livre Esclarecido (TCLE) e informado sobre os riscos e benefícios aos participantes, conforme preconiza a Resolução n ${ }^{\text {o }}$ 196/9614. O estudo foi aprovado pelo Comitê de Ética em Pesquisa da Universidade Federal do Piauí (CAAE No 0281.0.045.000-10).

\section{Resultados e Discussão}

Das 374 puérperas pesquisadas, três não realizaram pré-natal. A adesão à primeira consulta foi de $100 \%$. Sobre os profissionais que acompanharam o pré-natal, 120(32,09\%) foram atendidas exclusivamente pelo enfermeiro, $141(37,70 \%)$ pelo médico e $113(30,21 \%)$ tiveram consultas intercaladas entre médico e enfermeiro, ou seja, o enfermeiro foi o profissional nuclear no atendimento.

Observa-se uma concordância com relação à recomendação do Ministério da Saúde ${ }^{6}$ ao afirmar que as consultas de pré-natal e puerpério podem ser realizadas pelo profissional médico ou de enfermagem ou mesmo ser intercalada entre estes. Vale destacar que, de acordo com a lei de exercício profissional de enfermagem $n^{\circ} 7498 / 86^{15}$ e o Decreto $n^{0} 94.406 / 87^{16}$, o pré-natal de baixo risco pode ser inteiramente acompanhado pelo enfermeiro.

Outros estudos encontraram dados suficientes para afirmarem que as mulheres aprovam o pré-natal feito pelo enfermeiro, pois dizem que esses profissionais atendem com mais calma, sem pressa para ir embora, além de prestarem informações com uma linguagem mais fácil e compreensiva para elas ${ }^{17}$.

Somente $18(4,8 \%)$ puérperas receberam as três doses necessárias para uma cobertura vacinal adequada. A baixa cobertura vacinal foi caracterizada pelas oportunidades perdidas de vacinação (OPV), pois $289(77,5 \%)$ delas não receberam nenhuma dose da vacina, embora a maioria tenha realizado o pré-natal completo, conforme mostra a Figura 1.

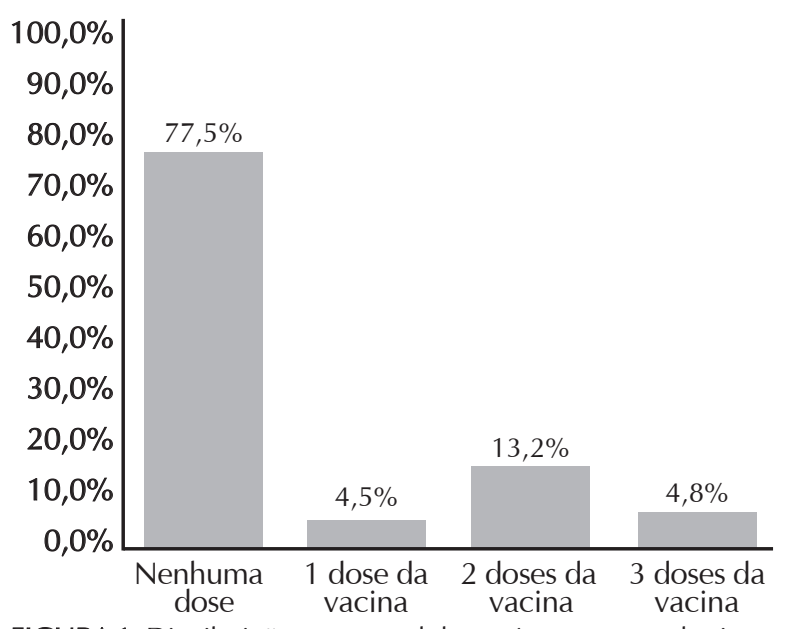

FIGURA 1: Distribuição percentual das puérperas segundo situação vacinal contra Hepatite B. Teresina - PI, 2011.

Estudos têm demonstrado que a negligência dos profissionais em observar o cartão de vacinas dos usuários, dentre outras atitudes negativas, tem se constituído em uma das principais causas de OPV e, consequentemente, contribuído para as baixas coberturas vacinais ${ }^{8,18}$. No caso de gestantes, a situação é mais crítica, pois a consulta pré-natal ocorre de forma sistemática e intercalada entre médico e enfermeiro, o que deveria ser um fator de proteção para não ocorrer OPV. Além desses profissionais, a gestante também é atendida pelo técnico de enfermagem e agente comunitário de saúde, sempre que comparece ao posto para a realização do pré-natal.

O uso da vacina contra Hepatite $\mathrm{B}$, na rotina do pré-natal, vem sendo utilizado ainda de forma bem tímida, principalmente devido ao desconhecimento dos profissionais sobre os benefícios associados. 
No ano de 2009, o PNI reforçou a indicação da vacinação contra a Hepatite $B$ em gestantes que apresentam sorologia negativa para Hepatitis B Surface Antigen ( $\mathrm{HBsAg}$ ) e naquelas que perderam a oportunidade de receber a vacina na rotina dos serviços. A gravidez não contraindica a vacinação, podendo ser realizada em qualquer idade gestacional ${ }^{11}$.

A consulta pré-natal é um momento oportuno para fazer o rastreamento da infecção pelo VHB, com vista à prevenção da transmissão vertical da infecção. Neste estudo, apenas 155 (41,4\%) puérperas realizaram exame sorológico para Hepatite B. Entre as que o realizaram, 99,1\% revelaram resultado não reagente (negativo) e 0,9\% indicaram resultado reagente (positivo). Estes dados coadunam com um estudo sobre marcadores sorológicos da Hepatite B em gestantes, no município de Vitória - ES e do noroeste paraense, os quais apresentaram, respectivamente, índices de $0,9 \%$ e $0,5 \%$ de positividade ${ }^{19,20}$.

Embora a prevalência de positividade para Hepatite $B$ tenha sido baixa entre as mulheres deste estudo e em demais regiões do Brasil, é importante ressaltar que a maioria delas não realizou a sorologia específica para a infecção, na ocasião do pré-natal. Somando-se tal fato às OPVs durante o pré-natal, verifica-se que muitos recém-nascidos permanecem expostos ao risco de contração e cronificação da doença. ${ }^{21}$.

Assim, a busca pela qualidade do pré-natal prevê exames básicos, entre eles, a sorologia para Hepatite B. Neste estudo, verificou-se associação estatisticamente significativa em relação à solicitação da sorologia para Hepatite B com algumas variáveis do pré-natal, ou seja, mulheres que iniciaram o pré-natal com idade gestacional acima 14 semanas $(\mathrm{OR}=1,54, \mathrm{p}<0,01$ e I.C $1,01-2,35)$, e o fizeram de forma incompleta $(\mathrm{OR}=1,92$, $\mathrm{p}<0,01$ e 1,23-3,01) tiveram uma chance maior de não realizar a sorologia para $\mathrm{HBsAg}$. Aquelas que realizaram o pré-natal no interior do Piauí $(\mathrm{OR}=3,27, \mathrm{p}<0,01$ e 2,13-5,04) apresentaram três vezes mais chances de não realizar esse exame. Sabe-se que um pré-natal realizado em locais com infraestrutura inadequada terá maior dificuldade em manter a oferta de exames básicos; entretanto, estudo feito em uma maternidade-escola, no município do Rio de Janeiro, identificou que quase metade das puérperas não realizaram exame para Hepatite $B$ no pré-natal e a maioria também não recebeu informações sobre este procedimento ${ }^{22}$. Portanto, a problemática da baixa cobertura do exame sorológico para Hepatite B permeia diferentes cenários de assistência à gestante no Brasil, de acordo com a Tabela 1.

TABELA 1: Modelo de regressão logística simples da realização da pesquisa HBsAg com as variáveis relacionadas ao pré-natal das puérperas do estudo. Teresina - $\mathrm{Pl}$, 2011. ( $(\mathrm{N}=374)$

\begin{tabular}{|c|c|c|c|c|c|c|c|}
\hline \multirow{3}{*}{ Variáveis } & \multicolumn{7}{|c|}{ Pesquisa HBsAg } \\
\hline & \multicolumn{2}{|c|}{ Não } & \multicolumn{2}{|c|}{ Sim } & \multirow{2}{*}{$\begin{array}{c}\text { Orna } \\
{ }_{(* *)}\end{array}$} & \multirow{2}{*}{$\begin{array}{c}\mathrm{p} \\
\text { valor } \\
(* * *)\end{array}$} & \multirow{2}{*}{ IC $95 \%$} \\
\hline & $f$ & $\%$ & $f$ & $\%$ & & & \\
\hline \multicolumn{8}{|l|}{ IG no início do pré-natal } \\
\hline$>14$ Semanas & 69 & 44,5 & 75 & 34,2 & 1,54 & 0,04 & $1,01-2,35$ \\
\hline Até 14 Semanas $\left.{ }^{*}\right)$ & 86 & 55,5 & 144 & 65,8 & & & \\
\hline \multicolumn{8}{|c|}{ Acompanhamento Pré-Natal } \\
\hline Incompleto & 59 & 38,1 & 53 & 24,2 & 1,92 & 0,01 & $1,23-3,01$ \\
\hline Completo & 96 & 61,9 & 166 & 75,8 & & & \\
\hline \multicolumn{8}{|c|}{ Local de realização do Pré-natal } \\
\hline Interior/outro estado & 102 & 65,8 & 81 & 37,0 & 3,27 & 0,01 & $2,13-5,04$ \\
\hline Capital & 53 & 34,2 & 138 & 63,0 & & & \\
\hline
\end{tabular}

Em relação às informações sobre a vacina contra Hepatite B, 289(77,3\%) puérperas foram informadas sobre as vacinas que deveriam receber por ocasião do pré-natal. Dentre as fontes informantes, o enfermeiro foi o mais citado, com $159(55,0 \%)$ indicações, reforçando o seu papel de destaque como um educador em saúde na atenção pré-natal. Ver Tabela 2.

Observa-se que as mulheres se sentiram à vontade para buscar informações com o enfermeiro, pois, geralmente, este profissional presta uma atenção mais integral durante o pré-natal, incluindo a educação em saúde. O contraponto foi o agente comunitário de saúde, cuja função precípua é a educação em saúde
TABELA 2: Distribuição das puérperas segundo recebimento de informações sobre as vacinas no pré-natal e profissional informante.Teresina-PI,2011

\begin{tabular}{lcc}
\hline \multicolumn{1}{c}{ Variáveis } & $f$ & $\%$ \\
\hline Recebeu Informações sobre as & & \\
vacinas (N=374) & 289 & 77,3 \\
Sim & 83 & 22,2 \\
Não & 2 & 0,5 \\
$\quad$ Não Lembra & & \\
Profissional que informou ( $\mathbf{n = 2 8 9 )}$ & 159 & 55,0 \\
$\quad$ Enfermeiro & 107 & 37,0 \\
$\quad$ Médico & 20 & 7,0 \\
Agente Comunitário de Saúde & 3 & 1,0 \\
$\quad$ Demais profissionais & & \\
\hline
\end{tabular}


e foi possível observar a lacuna deixada por eles com relação ao quesito orientação para a vacinação.

As mulheres estabelecem uma maior relação de confiança com o enfermeiro, o que facilita na hora de perguntarem algo que não entenderam ${ }^{17}$. Entretanto, o simples recebimento de informações não assegura que estas serão bem assimiladas pelo grupo. Isso alerta para a necessidade de o enfermeiro refletir sobre a sua postura nas atividades educativas, que valorize a participação ativa da gestante nos grupos de educação e saúde ${ }^{22,23}$. Para tanto, é necessária a interação do profissional com a gestante, para desenvolver sua confiança, aumentar a credibilidade e, assim, promover uma relação de trocas de conhecimentos. Nessa perspectiva, é importante considerar a consulta de enfermagem como um espaço importante para a realização de ações educativas ${ }^{24}$ e como alerta para a qualidade do atendimento do profissional, principalmente do enfermeiro, que é responsável pelo acolhimento na porta de entrada do serviço.

Considera-se limitação do estudo, porém não suficiente para comprometê-lo, a inadequada qualidade do preenchimento de informações no cartão da gestante, uma vez que a situação vacinal das puérperas foi levantada por meio da sua observação. Assim, podem ter recebido vacinas que não foram registradas.

\section{Conclusão}

Os resultados deste estudo permitiram concluir que a maioria das puérperas realizou pelo menos uma consulta de pré-natal. Entretanto, evidenciou-se a ocorrência de baixas coberturas sorológicas e vacinais para Hepatite B, apontando a necessidade de sensibilização de todos os profissionais de saúde que realizam o pré-natal, para que se envolvam na importância da vacinação, visto que não se justifica a mulher comparecer à consulta e não ser vacinada nesta ocasião.

Muitos são os desafios para equacionar esta problemática, que englobam aspectos assistenciais, sociais e individuais. Portanto, para seu enfrentamento, as ações devem ser ampliadas para além dos serviços de saúde, com a adoção de uma abordagem não meramente biológica, mas que contemple a mulher em sua plenitude.

Ressalta-se que o enfermeiro, profissional inserido em todos os níveis da atenção à mulher e criança, pode e deve colaborar na superação destes desafios. E pelo seu destaque na atuação efetiva da prevenção e promoção da saúde, pode contribuir individualmente, nas consultas de enfermagem, realizadas na estratégia saúde da família, nas visitas domiciliares e em atividades desenvolvidas nas maternidades ou centros de parto normal, para a melhoria das coberturas vacinais do público que recebe seu atendimento.

Assim, propõe-se uma reflexão sobre como os profissionais de saúde, gestores dos serviços de saúde e a comunidade em geral poderão contribuir para a melho- ria da cobertura vacinal e para a solicitação do exame sorológico para Hepatite B. Ao citar a comunidade nesta tríade, a intenção foi chamar a atenção para a ideia de que só será possível atender às metas de vacinação se houver um esforço conjunto da sociedade como um todo.

\section{REFERÊNCIAS}

1.Santos NOS, Romanos MTV, Wigg MD. Introdução à virologia Humana. $2^{\mathrm{a}}$ ed. Rio de Janeiro: Guanabara Koogan; 2008.

2.Focaccia R, Veronesi R. Tratado de Infectologia. São Paulo: Atheneu; 2009

3.Ministério da Saúde (Br). Secretaria de Vigilância em Saúde. Departamento de DST, Aids e Hepatites Virais. Protocolo clínico e diretrizes terapêuticas para o tratamento da hepatite viral crônica B e confecções. Brasília (DF): Ministério da Saúde; 2010.

4.Ministério da Saúde (Br). Secretaria de Vigilância em Saúde. Sistema nacional de vigilância em saúde: relatório de situação: Piauí. $5^{\mathrm{a}}$ ed. Brasília (DF): Ministério da Saúde; 2011

5.Araújo TME, Sá LC, Santos AS, Faustino SKM, Tapety FI. Prevalência da hepatite B em usuários do laboratório Central do Piauí. Rev enferm UERJ [Internet]. 2012 [citado em 30 mai 2013]. 20; 229-34. Disponível em: http://www.facenf.uerj.br/v20n2/v20n2a15.pdf

6.Ministério da Saúde (Br). Secretaria de Atenção à Saúde: Departamento de Ações Programáticas Estratégicas: Área Técnica de Saúde da Mulher. Pré-natal e Puerpério: atenção qualificada e humanizada - manual técnico. Brasília (DF): Ministério da Saúde; 2006

7.Hinrichsen SL. DIP. Doenças infecciosas e parasitarias. Rio de Janeiro: Guanabara Koogan; 2005

8.Araújo TME. Vacinação infantil: conhecimentos, atitudes e práticas da população da Área Norte/Centro de Teresina/PI. [tese doutorado]. Rio de Janeiro: Universidade Federal do Rio de Janeiro; 2005.

9.Secretaria Estadual da Saúde do Piauí (Sesapi). Coordenação Estadual de Imunização. Série Histórica de vacinação da Hepatite B. Teresina (PI): Sesapi; 2011.

10.Ferreira CT, Silveira TR. Hepatites virais: aspectos da epidemiologia e da prevenção. Rev Bras Epidemiol. [Scielo-Scientific Electronic Library Online] 2006 [citado em 18 maio 2013]. 7:473-87

11.Medeiros, SLC. Soroprevalência da infecção pelo vírus da Hepatite B em usuários de crack no Piauí. [Dissertação de Mestrado]. Teresina (PI): Universidade Federal do Piauí; 2013.

12.Ministério da Saúde $(\mathrm{Br})$. Nota técnica conjunta $\mathrm{n}^{\mathrm{O}}$ 02/2013 CGPNI/DEVEP e CGDHRV/DST-AIDS/SVS/ MS. Ampliação da oferta da vacina Hepatite B para a faixa etária de 30 a 49 anos em 2013. Brasília (DF): MS; 2013. 13. Ministério da Saúde (Br). Informe técnico da introdução da vacina pentavalente. CGPNI/DEVEP/SVS/ MS. Brasília (DF): MS; 2012.

14.Ministério da Saúde (Br). Conselho Nacional de Saúde - CNS. Diretrizes e Normas Regulamentadoras de Pesquisas Envolvendo Seres Humanos. Resolução n ${ }^{\circ}$ 
196/96. Brasília (DF): Ministério da Saúde; 1996.

15. Presidência da República, (Br). Lei n ${ }^{\circ} 7498$, de 25 de junho de 1986. Dispõe sobre a regulamentação do exercício da enfermagem, e dá outras providências [Internet]. Brasília (DF); 1986. [citado em 30 mai 2013]. Disponível em: http:// www.jusbrasil.com.br/ legislação/128195/lei-7498-86.

16.Conselho Federal de Enfermagem. Decreto n ${ }^{\circ} 94.406$, de 08 de junho de 1987. Regulamenta a lei $n^{\circ} 7.498$ e da outras providencias. [Internet]. Brasília (DF); 1987. [citado em 30 mai 2013]. Disponível em: http://www. cofen.gov.br/decreto-n-9440687 4173.html.

17. Shimizu HE, Lima MG. As dimensões do cuidado prénatal na consulta de enfermagem. Rev Bras de Enferm. [internet] 2009 [citado em 18 mai 2013]. 62; 387-92. Disponível em: http://www.scielo.br/scielo.php?pid=S0034 $71672009000300009 \&$ script $=$ sci_arttext.

18.Organização Pan-americana da Saúde. Oportunidade Perdida de Vacinação. Brasília (DF): OPS; 1985.

19.Figueiredo NC, Page-Shafer K, Pereira F E L, Miranda A E . Marcadores sorológicos do vírus da Hepatite B em mulheres jovens atendidas pelo Programa de Saúde da Família em Vitória, Estado do Espírito Santo, 2006. Revista da Sociedade Brasileira de Medicina Tropical [Scielo-Scientific Electronic Library Online] 2005 [citado em 05 set 2013]. 58:590-5. Disponível em: http://www.scielo.br/prc
20.Ferezin RI, Bertolini DA, Demarchi IG. Prevalência de sorologia positiva para HIV, hepatite B, toxoplasmose e rubéola em gestantes do noroeste paranaense. Rev Bras Ginecol Obstet. [Scielo-Scientific Electronic Library Online] 2013 [citado em 28 mai 2015]; 35:66-70.Disponível em: http://www.scielo.br/prc.

21.Piazza MJ, Urbanetz AA, Carvalho NS, Nascimento DJ. Hepatites virais e gestação. Diagn Tratamento. 2010; 15(1):12-8

22.Silva CF, Araújo CLF, Araújo MM. Oferta do teste sorológico para Hepatite B durante o pré-natal: a vivência das puérperas. Rev enferm UERJ. 2015; (citado em 28 mai 2015). 23:58-63. Disponível: http://www.facenf. uerj.br/v23n1/v23n1a10.pdf

23.Pereira SVM, Bachion MM. Diagnósticos de enfermagem identificados em gestantes durante o pré-natal. Rev Bras Enferm. [Scielo-Scientific Electronic Library Online] 2005 [citado em 18 mai 2013]. 58:559-64. Disponível em: http://www.scielo.br/prc

24.Rios CTR, Vieira NFC. Ações educativas no prénatal: reflexão sobre a consulta de enfermagem como um espaço para educação em saúde. Ciênc saúde coletiva. [Scielo-Scientific Electronic Library Online] 2007 [citado em 18 mai 2013]; 12:477-86. Disponível em: http://www.scielo.br/prc. 